\title{
Aspectos de regulação internacional do petróleo: o caso Brasil
}

\author{
THAIZ DA SILVA VESCOVI CHEDID ${ }^{I}$ \\ e EDMILSON MOUTINHO DOS SANTOS ${ }^{I I}$
}

\section{Introdução}

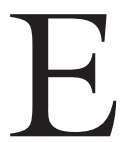

STE TRABALHO divide-se em duas etapas. Primeiramente, pretende verificar os aspectos de regulação internacional do petróleo, mais precisamente aqueles previstos na Convenção das Nações Unidas sobre o Direito do Mar de 1982 no que tangem à obrigatoriedade do pagamento às Nações Unidas de royalties advindos da exploração dos hidrocarbonetos nas plataformas estendidas. Feito isso, busca tratar do tema a partir de um estudo de caso do estado brasileiro.

Visa abordar o viés econômico do direito do mar, como se dá a exploração marítima dos recursos naturais, bem como os aspectos históricos offshore. Ademais, aponta as características básicas, a origem e a evolução do conceito dos royalties no âmbito nacional brasileiro e internacional, trazendo à tona $\mathrm{o}$ histórico do aludido pagamento em solo brasileiro e a legislação pertinente.

Dito isso, adentra os institutos da Convenção das Nações Unidas sobre o direito do Mar de 1982 (partes legítimas, os requisitos e fundamentos para pagamento dos royalties, as características das plataformas continentais geológicas e sua classificação, assim como pagamento como mecanismo de garantia dos direitos humanos, fundamentais e sociais e patrimônio comum da humanidade, e sua destinação à Autoridade Internacional dos Fundos Marinhos). Para isso, o trabalho utilizará o método dedutivo e o tipo de pesquisa exploratório e comparativo.

Por fim, busca-se analisar a aplicação do aludido instituto jurídico no Brasil, trazer as consequências do descumprimento da Convenção de Montego Bay pelo Estado brasileiro perante a Autoridade Internacional de Fundos Marinhos e o Tribunal do Mar, a efetividade da decisão, e as consequências para o país. $\mathrm{O}$ tema mostra relevância tendo em vista a localização das plataformas exploratórias offshore brasileiras atuais - já próximas do limite previsto em lei - e o tracejado do polígono do pré-sal - que adentram nas 200 milhas marítimas previstas na Convenção - sendo este um cenário não iminente. 


\section{Direito do Mar e seu viés econômico exploratório}

A vida humana depende do mar; justamente por isso, essa imensidão de espaço que engloba $72 \%$ da superfície terrestre é historicamente palco de disputas, e, por conta disso, a sociedade internacional achou necessária a confecção de regulamentos que tornassem a sua utilização o mais racional possível.

Dito isso, cumpre saber qual é o significado do termo "direito do mar" e sua relação com a área econômica, particularmente na dimensão da exploração offshore de recursos naturais e hidrocarbonetos, para poder-se adentrar posteriormente o tema da distribuição de royalties advindos dessa exploração e das relações que se estabelecem com as Nações Unidas. Importante tal definição tendo em vista que o tema carece de estudos aprofundados, tanto no campo do direito internacional como nas discussões de política energética, que ora nos propomos a fazê-lo em pesquisa interdisciplinar.

Sobre a relação do direito do mar com o direito internacional:

The development of the law of the se ais inseparable from the development of international law in general. It grew up only when the emergence of independent States made possible truly international relations, instead of the imperial relations which subsisted throughout the life of the Holy Roman Empire. (Churchill; Lowe, 1988, p.14)

$\mathrm{Na}$ seara jurídica, o direito marítimo se classifica em direito marítimo público (tráfego, segurança e aspectos metaindividuais) e direito marítimo privado (comércio e indústria). Dentro do direito marítimo público, temos o direito internacional marítimo ou direito do mar e o direito internacional marítimo ambiental. Neste trabalho, analisar-se-á fundamentalmente o direito internacional marítimo ou direito do mar. Sobre o direito do mar, explica Sampaio de Lacerda $(1984$, p.334) que são:

a) normas de direito público marítimo, ou melhor, do direito marítimo administrativo e penal, compreendendo as normas relativas à Marinha Mercante, à Polícia dos Portos, à organização e funcionamento dos Tribunais Marítimos.

b) normas de direito internacional marítimo: público ou privado. As primeiras regulam a liberdade dos mares, o direito e obrigações entre beligerantes e neutros. As segundas ocupam-se em solucionar os conflitos de leis derivados da navegação marítima; c) normas de direito comercial marítimo ou de direito marítimo privado, ou ainda de direito civil marítimo que são as que regem a armação e expedição de navios e as relações decorrentes dos fatos inerentes à navegação.

Em geral, a terminologia "direito marítimo" remonta ao conjunto de normas jurídicas que regulamentam toda e qualquer atividade originária do uso dos bens e meios para navegação, exploração do mar e das águas interiores, em superfície ou submersa, seja qual for a sua finalidade e objetivo. 
Então, no que tange ao "direito internacional marítimo" ou "direito do mar”, esse pode ser definido como o conjunto de normas jurídicas de âmbito internacional que regulam matérias como transporte internacional, a liberdade dos mares, o limite do mar territorial, zonas contíguas, zonas econômicas e regras relativas à preservação do meio ambiente. Esse ramo do direito nada mais é do que o balanceamento e equilíbrio entre o princípio da liberdade dos mares e a soberania nacional dos países (O’Conell, 1978, p.435).

Dentre os principais instrumentos normativos do direito do mar encontram-se a Convenção de Genebra de 1958 e a Convenção das Nações Unidas sobre o Direito do Mar de 1982 (Studier, 1980, p.5). Os aludidos diplomas legais estabeleceram conceitos utilizados até hoje no âmbito dos espaços marítimos, tais como: águas interiores, mar territorial, alto mar, plataforma continental, plataforma estendida, zona internacional dos fundos dos mares, dentre outros.

Diante de tamanha abrangência, torna-se praticamente impossível não relacionar o direito do mar com o viés econômico. Vale dizer, portanto, que o Direito Marítimo não apenas sofre grande influência da economia internacional, como interage diretamente com o interesse público e as demandas dos agentes econômicos e usuários dos espaços e serviços marítimos.

A globalização, também caracterizada pelo processo de integração econômica internacional que envolve contratos e regulamentações, ressalta a necessidade de integração e cooperação entre os países, transportes, importação e exportação, muitas vezes, possível por meio do mar. Em razão do rápido avanço tecnológico e da concorrência entre as nações e os agentes econômicos globais para explorar os recursos minerais e energéticos alocados no mar, torna-se cada vez mais relevante regulamentar a produção de bens e a prestação de serviços alocados nas zonas marítimas.

Nesse contexto, a consolidação de regras aceitas pela comunidade internacional permitirá que os agentes econômicos possam buscar formas ou modelos econômicos adequados para a exploração e valorização de recursos naturais em novas fronteiras. São regiões inóspitas que desafiam a capacidade de investimento e de desenvolvimento tecnológico das nações. O sucesso dessa exploração requer um melhor desempenho dos agentes econômicos e o diálogo mais construtivo entre diferentes grupos de interesses nacionais e globais.

Dados governamentais (Brasil, 2013) demonstram que o país que detém e controla reservas petrolíferas e mantém uma estrutura adequada de refino tem vantagens competitivas sobre setores vitais da economia interna (como transporte e produção de eletricidade) e da indústria, pela participação no comércio internacional e pela exportação direta do óleo e seus derivados.

Dito isso, importante delimitar também que tal tema global será tratado a partir de um estudo de caso do Brasil. Vale lembrar que grande maioria $(90 \%)$ do petróleo produzido no Brasil vem de campos offshore. Até o momento, contabilizam-se 111 plataformas offshore ao longo da costa brasileira. Com as reser- 
vas de pré-sal, o Brasil deve consolidar sua autossuficiência no combustível fóssil e transformar-se em exportador, aumentando a produção atual de 14,4 bilhões de barris de petróleo para 70 a 107 bilhões de barris de petróleo.

\section{Convenção das Nações Unidas sobre o Direito do Mar de 1982}

$\mathrm{Na}$ verdade, ventos e correntes marítimas não respeitam linhas divisórias fixadas em terra ou nos espaços aquáticos ou aéreos, por critérios humanos, nem as aves migratórias ou os habitantes dos mares e oceanos necessitam de passaportes para atravessar fronteiras, as quais foram delimitadas, em função dos homens.

Da mesma maneira Francisco Rezek (2010) aponta que a expressão domínio público internacional designa aqueles espaços (mar, espaço aéreo, rios internacionais etc.) cuja utilização suscita o interesse de mais de um Estado soberano - às vezes de toda a comunidade internacional, ainda quando sujeitos à incidência de determinada soberania.

No mesmo sentido, Keith Maskus (2005, p.569) lembra que:

Under current international law, traditional crops bred and developed over generations by customary and informal farming practices, as well as landraces not systematically used, are subject to the principle of permanente sovereingnty over natural resource. Governments are free to regulate their use and ownership within bounds of international agréments in force for state parties.

Assim, nesse caso, o aproveitamento dos recursos naturais poderá ser regulamentado tanto pelo direito interno como pelo direito Internacional, dependendo do local em que se encontrar (Rezek, 2010). Resta dizer: O Alto Mar é espaço pertencente a todos, justamente por isso, nenhum Estado poderá exercer sua soberania sobre ele.

Essa tese foi consagrada no artigo 136 da Convenção de Montego Bay, na qual se explicita que a "Área" (fundos oceânicos) e seus recursos são patrimônio comum da humanidade, e nenhum Estado pode reivindicar ou exercer soberania, sobre qualquer parte da Área ou seus recursos. O parágrafo segundo do art. 137, da aludida Convenção também expõe que todos os direitos sobre os recursos da Área pertencem à humanidade em geral, em cujo nome atuará a Autoridade.

\section{Requisitos e fundamentos para o pagamento}

Conforme disposto na Convenção das Nações Unidas sobre o Direito do Mar, os requisitos e fundamentos para o pagamento dos royalties relacionam-se substancialmente com a localização da plataforma. Se a plataforma localizar-se até o limite de 200 milhas marítimas, não se faz necessário o pagamento dos royalties.

A Figura 1 elucida bem a afirmativa.

Já se a plataforma localizar-se além das 200 milhas marítimas (plataforma estendida) e o país não for importador do recurso ali explorado, seria devido o pagamento dos royalties às Nações Unidas (Clain, 1985, p.557). 
Novamente destaca-se na aludida Convenção (CNUDM) (Marotta Rangel, 1985, p.320) que, para o estado costeiro poder explorar os recursos nas plataformas estendidas, deve apresentar uma proposta de delimitação da plataforma continental jurídica para além das 200 milhas marítimas junto às Nações Unidas, desde que não ultrapasse 350 milhas marítimas da linha de base. Essa área pode ser chamada de plataforma continental estendida.

Cumpre lembrar que essa plataforma estendida localizar-se-ia na região denominada "Área" (zona dos fundos marinhos) pelo art. $1^{\circ}$ da referida Convenção, que equivale ao leito do mar, fundos marinhos e subsolo além dos limites da jurisdição nacional. Tanto a Área como os seus recursos são património comum da humanidade segundo o art. $136^{\circ}$ da CNUDM.

Conforme dispõe o art. 82 da Convenção das Nações Unidas sobre o Direito do Mar (Rezek, 2010):

Artigo 82. ${ }^{\circ}$ Pagamentos e contribuições relativos ao aproveitamento da plataforma continental além de 200 milhas marítimas.

l - O Estado costeiro deve efetuar pagamentos ou contribuições em espécie relativos ao aproveitamento dos recursos não vivos da plataforma continental além de 200 milhas marítimas das linhas de base, a partir das quais se mede a largura do mar territorial.

2 - Os pagamentos e contribuições devem ser efetuados anualmente em relação a toda a produção de um sítio após os primeiros cinco anos de produção nesse sítio. No sexto ano, a taxa de pagamento ou contribuição será de $1 \%$ do valor ou volume da produção no sítio. A taxa deve aumentar $1 \%$ em cada ano seguinte até ao décimo segundo ano, e daí por diante deve ser mantida em $7 \%$. A produção não deve incluir os recursos utilizados em relação com o aproveitamento.

3 - Um Estado em desenvolvimento que seja importador substancial de um recurso mineral extraído da sua plataforma continental fica isento desses pagamentos ou contribuições em relação a esse recurso mineral.

4 - Os pagamentos ou contribuições devem ser efetuados por intermédio da Autoridade, que os distribuirá entre os Estados Partes na presente Convenção na base de critérios de repartição equitativa, tendo em conta os interesses e necessidades dos Estados em desenvolvimento, particularmente entre eles, os menos desenvolvidos e os sem litoral.

É por intermédio da Autoridade dos Fundos Oceânicos que devem ser efetuados esses pagamentos ou contribuições, que, por sua vez, seriam distribuídos na base de critérios de repartição equitativa, tendo em conta os interesses e necessidades dos Estados em desenvolvimento, particularmente, entre eles, os menos desenvolvidos e sem litoral, conforme expõe a Convenção de Montego Bay, art. 82, parágrafo $4^{\circ}$.

\section{Destinação}

Antes de apontar as consequências previstas pela Convenção de Montego Bay (Marotta Rangel, 1985, p.320) para os Estados-parte signatários que des- 
LIMITES DO MAR

1 MILHA NÁUTICA $=1.852 \mathrm{~m}$

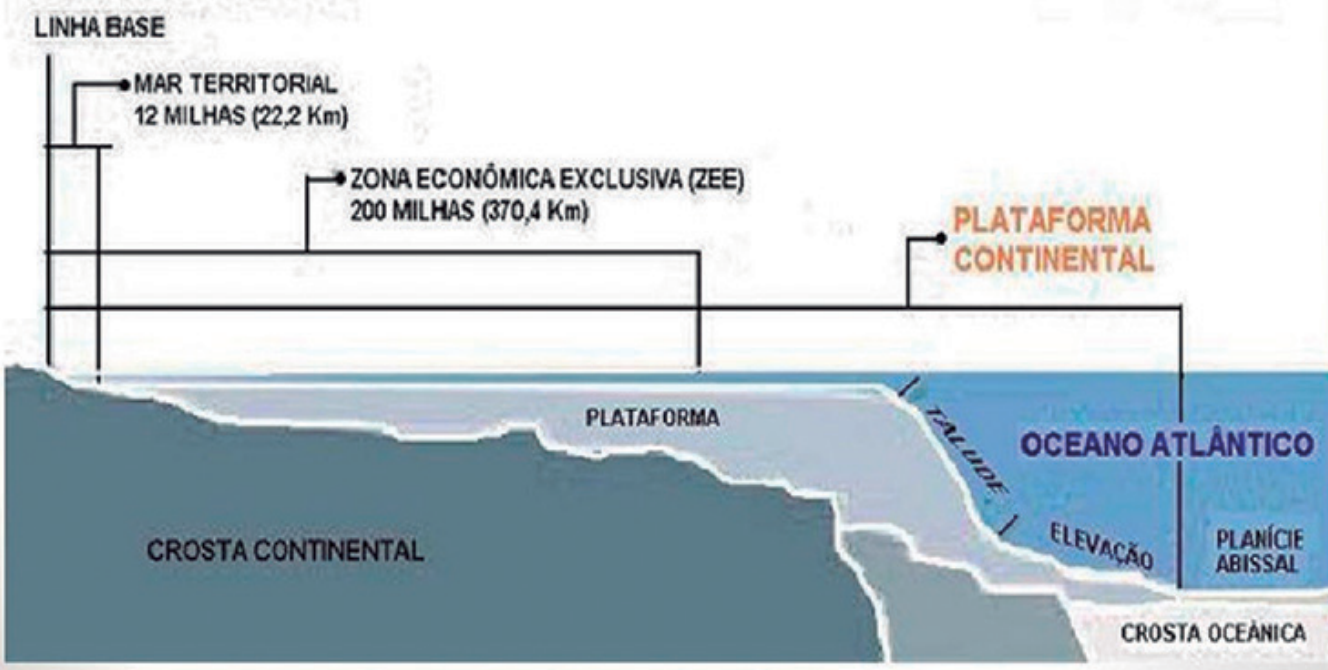

Fonte: Marinha do Brasil.

Figura 1 - Limites do Mar I.
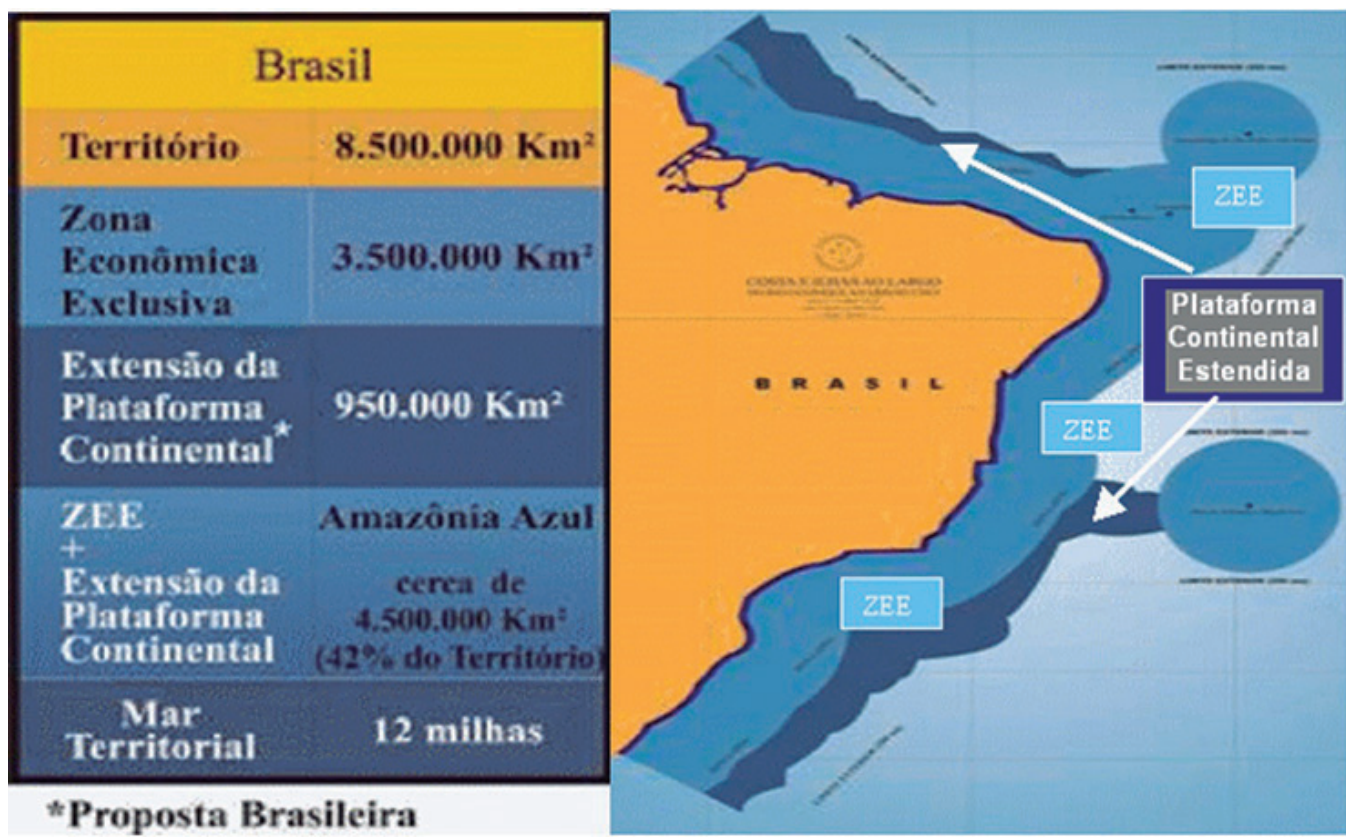

*Proposta Brasileira

Fonte: Marinha do Brasil.

Figura 2 - Limites do Mar II. 
cumprirem com as regras previstas em seu preceito, vale lembrar que, antes de tudo, os Estados precisam preservar sua imagem e compromisso com sua postura no cenário internacional.

Isso é possível quando agem zelando pelo cumprimento das suas obrigações internacionais, fundamentalmente aquelas relativas à proteção e preservação do patrimônio comum, seja ele o mar, o ar, seja qualquer outro direito difuso. Não o fazendo, serão responsabilizados em conformidade com o direito internacional.

No que tange à previsão dessa responsabilização pela Convenção de Montego Bay, o art. 229 da Convenção estabelece em seu artigo 139 que os Estados- parte devem zelar pelo cumprimento das atividades em seu território de acordo com as regras da Convenção, e o não cumprimento de suas obrigações e os danos causados implicam responsabilidade (Rezek, 2010):

Artigo $139^{\circ}$ Obrigação de zelar pelo cumprimento e responsabilidade por danos

1 - Os Estados Partes ficam obrigados a zelar por que as atividades na área, realizadas quer por Estados Partes, quer por empresas estatais ou por pessoas jurídicas, singulares ou coletivas, que possuam a nacionalidade dos Estados Partes ou se encontrem sob o controlo efetivo desses Estados ou dos seus nacionais, sejam realizadas de conformidade com a presente parte. A mesma obrigação incumbe às organizações internacionais por atividades que realizem na área; 2 - Sem prejuízo das normas de direito internacional e do artigo $22 .^{\circ}$ do anexo III, os danos causados pelo não cumprimento por um Estado Parte ou uma organização internacional das suas obrigações, nos termos da presente parte, implicam responsabilidade; os Estados Partes ou organizações internacionais que atuem em comum serão conjunta e solidariamente responsáveis. No entanto, o Estado Parte não será responsável pelos danos causados pelo não cumprimento da presente parte por uma pessoa jurídica a quem esse Estado patrocinou nos termos da alínea.

Corroborando com o tema da responsabilidade, XV secção II da Convenção prevê três órgãos para vigiar seu cumprimento, encontrando-se em pleno funcionamento, são eles: a Autoridade Internacional para os Fundos Marinhos (sediada em Kingston, Jamaica); o Tribunal Internacional sobre Direito do Mar (sediado em Hamburgo, Alemanha); a Comissão dos Limites da Plataforma Continental (que está instalada na Sede das Nações Unidas em Nova York).

Cada um dos órgãos possui competência de acordo com a localização da atividade. Para este trabalho, interessa-nos saber que as atividades na Área (Zona dos Fundos Oceânicos) são organizadas, conduzidas e controladas/administradas pela Autoridade Internacional para Fundos Marinhos. Nesse órgão podem litigar os Estados-parte, a Autoridade, empresas estatais e pessoas físicas e jurídicas capacitadas para exercer atividades na Área. 
Quando a controvérsia relativa à Área ocorre entre Estados-Partes, a competência da Autoridade não é exclusiva, podendo ser confiada a uma Câmara Especial do Tribunal Internacional sobre Direito do Mar, constituída ex officio ou a pedido das partes, ou a uma Câmara $a d$ hoc da própria Câmara para a solução de Controvérsias relativas aos Fundos Marinhos, do Tribunal. Podendo ainda ser também dirimida junto à Corte Internacional de Justiça ou pela Arbitragem Especial.

É importante destacar que apesar da Convenção se referir aos outros órgãos como forma de solução pacífica de conflitos, no âmbito dos órgãos por ela criados, apenas o Tribunal Internacional de Direito do Mar e a Autoridade Internacional dos Fundos Marinhos tem caráter para solucionar e administrar os litígios por meios judiciais, respectivamente.

Justamente por isso, não será tratado neste estudo dos outros órgãos mencionados, pois estar-se-ia fugindo do contexto central do nosso estudo. Trataremos, por outro lado, de forma mais específica da Autoridade Internacional dos Fundos Marinhos a seguir.

\section{A Autoridade internacional dos fundos marinhos}

Criada pela Convenção das Nações Unidas sobre o Direito do Mar (CNUDM), a Autoridade Internacional dos Fundos Marinhos é uma organização internacional intergovernamental sediada em Kingston, Jamaica, para atuar em nome da humanidade sobre a organização e controle das atividades da "Área", com poderes que vão desde a edição de regras gerais e obrigatórias até a execução de atos de natureza comercial, localizados na "Área".

Além dos poderes, a Convenção do Mar de 1982 estabeleceu também alguns limites à atuação da Autoridade Internacional dos Fundos Marinhos, a saber: a) limite material; b) limite espacial; e c) limite jurídico.

Objetivamente, o primeiro trata dos artigos 153 e 157 da Convenção de Montego Bay, que aponta para o limite material quando expõe que por "atividades da Área" são entendidas todas as atividades de exploração e aproveitamento dos recursos na Área. Mas não define cada um desses termos, que passaram a ser definidos pela doutrina.

O limite espacial, por sua vez, delimita a atuação da Autoridade apenas à Área, ou seja, o espaço marítimo que começa no limite exterior da plataforma continental, compreendendo o leito do mar, os fundos marinhos, bem como o espaço aéreo acima deles, exceto o previsto no art. 82, parágrafo 4, da Convenção (Dipla, 1985, p.400).

Já o limite jurídico estabelece que a Autoridade deverá, no exercício de suas competências, ter como pressuposto básico o respeito ao quadro jurídico imposto pela Convenção de Montego Bay, bem como seus anexos, regras, regulamentos e procedimentos, exercendo suas funções em conformidade com as regras estabelecidas em seu ato constitutivo, conforme art. 157, parágrafo segundo, da CNUDM (Marotta Rangel, 1985, p.320). 
Vale dizer, ainda, que a Autoridade tem sua estrutura orgânica composta por três órgãos, a saber: 1) Assembleia; 2) Conselho; e 3) Secretariado. A primeira tem o objetivo de ser um órgão plenário composto por representantes de cada estado parte para análise de dispositivos da Convenção de 1982. O segundo trata-se de um órgão executivo da Autoridade que ainda atua diante de inúmeros questionamentos e debates. Interessa-nos, aqui, especialmente o terceiro: o secretariado.

Isso, pois, havendo o pagamento de royalties às Nações Unidas, é o Secretariado da Autoridade Internacional dos Fundos Marinhos quem receberá o montante e dará sua efetiva destinação. $\mathrm{O}$ secretariado tem semelhança com os secretariados de outras organizações internacionais, tendo um papel importante de ajustes para consulta e cooperação internacional com outras organizações internacionais. Ademais, irá cobrar os percentuais constantes do artigo 82, depois do período de graça de cinco anos iniciais, aos estados-parte que explorarem além das 200 milhas marítimas, caso do Brasil.

\section{Estudo de caso: Brasil}

Antes de avançar na legislação brasileira acerca dos royalties, cumpre-se fazer um breve apontamento sobre a terminologia e conceito do termo. Nessa nota inicial, há de se enfatizar o papel desse instrumento econômico e jurídico tanto no plano dos Estados nacionais, como na dimensão internacional relacionada a atividades desenvolvidas no âmbito das Nações Unidas.

\section{Royalties do Estado nacional e das Nações Unidas}

No que tange aos "royalties", é de conhecimento público e notório que esses constituem-se numa das formas mais antigas de pagamento de direitos sobre atividades econômicas. A terminologia "royalties" advém da Inglaterra, onde o rei (royal) era detentor dos recursos não renováveis a serem explorados, como apontou Gilberto Bercovici (2011, p.105-6); senão, vejamos:

A palavra royalty vem do inglês "royal", que significa "da realeza" ou "relativo ao rei" e refere-se ao fluxo de pagamentos ao proprietário de um ativo não renovável que o cede para ser explorado, usado ou comercializado por terceiros [...] Ao se introduzir a dimensão de escassez do petróleo e do gás, os royalties podem ser encarados como uma forma de apropriação pela sociedade de parcela da renda gerada pela exploração e produção desses recursos não renováveis.

Dito isso, "royalties" sempre se caracterizam como pagamentos feitos por uma parte, o licenciado, autorizado ou franqueado, a outro que possui o direito de propriedade sobre um determinado ativo, o licenciante ou franqueador, pelo direito de uso contínuo desse ativo. Há diferentes modos ou métricas de se calcular os "royalties" como compensação justa e adequada a ser paga. Tipicamente, "royalties" são acordados como uma porcentagem das receitas brutas ou líquidas derivadas do uso de um particular ativo, ou como um preço fixo por unidade vendida de um determinado bem. 
Um contrato de licença ou concessão de uso (ou exploração) define os termos sob os quais um recurso ou propriedade é licenciado a um interessado. Essa cessão frequentemente é sujeita a restrições, incluindo, por exemplo, limitação de prazo, delimitação do escopo do negócio ou de território geográfico alcançado, ou, mesmo, de tipo de produto sob foco. Os contratos de licença ou concessão podem ser regulamentados, particularmente onde um governo é o proprietário do recurso, ou podem ser contratos privados que seguem estruturas gerais dessa classe de contratos.

Certos tipos de acordos de franquia são muito conhecidos e seguem disposições comparáveis, tais como: (i) exploração de patentes, marcas ou de imagem; (ii) direitos autorais diversos; (iii) exploração de tecnologias ou modelos de negócio, principalmente em acordos de alianças estratégicas; (iv) exploração de bens e serviços públicos, incluindo diferentes monopólios naturais regidos ou controlados por governos; e (v) exploração de recursos minerais, incluindo hidrocarbonetos como petróleo, carvão ou gás natural.

Ao discutir temas relacionados à definição de valores justos e adequados dos "royalties", depara-se com problemáticas econômicas essenciais de estimativa rigorosa dos termos avaliação dos ativos envolvidos e sua capacidade de geração de riqueza presente e futura. Esses processos de avaliação tendem a ser complexos na definição das métricas específicas a serem utilizadas, mas também nos processos de negociação que precisam ser estabelecidos entre as partes para incluir as diferentes circunstâncias dentro das quais o negócio se desenvolverá.

Sem poder trazer um aprofundamento normativo, a ideia de pagamento de "royalties" para as Nações Unidas, pela exploração de "bens humanitários", cuja propriedade não pode ser atribuída a nenhuma nação ou interesse privado, pode ser interpretada como uma extensão do termo e seu conceito. Na verdade, nessa aplicação estendida, os "royalties" pagos às Nações Unidas passam a constituir elementos importantes e com papel crescente na nova ordem de governança global. Há vários outros desdobramentos que podem ser explorados no futuro e que poderão constituir novas linhas de pesquisa. ${ }^{1}$

\section{Royalties sobve exploração do petróleo no Brasil}

Voltando-se à temática da definição e pagamento de "royalties" sobre atividades de exploração e produção de petróleo e gás natural no Brasil, necessário se faz, primeiramente, contextualizar o tema traçando um breve histórico sobre a questão legislativa do petróleo no país.

No que diz respeito especificamente ao petróleo no Brasil, há registros de algumas autorizações para exploração já no período imperial em favor dos ingleses Thomas Sargent e Edward Wilson, pelo prazo de 30 anos no território da Bahia (Calógeras, 2001 v.III , p.59-74), além de outras autorizações na província de São Paulo, Santa Catarina, Maranhão, dentre outras.

Porém, o enfoque dado ao petróleo ganhou destaque fundamentalmente, após a Primeira Guerra Mundial, na França, onde ficou clara a necessidade do 
controle nacional do petróleo e combustíveis. Nesse período, o governo francês estabeleceu normativas que atribuíam à França a titularidade do monopólio de importação de petróleo e derivados, garantindo a proteção alfandegária ao refino em território nacional.

No Brasil, a Constituição Republicana de 1981, em seu artigo 72, parágrafo 17, também rompeu com o sistema anterior de propriedade de solo, instituindo o regime de acessão, atribuindo ao proprietário do solo também a propriedade do subsolo, que manteve-se inalterado pelo Código Civil de 1916 (ibidem, p.74-6).

Segundo Gabriel Cohn (1968, v.1, p.11), até a revolução de 1930, o petróleo ainda não era um problema nacional. Após essa data o tema passa a se tornar uma preocupação global e centralizadora do estado nacional, principalmente com o surgimento do Código de Minas de 1934 (Decreto n.24.642 de 1934) que trouxe em seu artigo $4^{\circ}$ a abolição do regime de acessão, separando a propriedade do solo da propriedade do subsolo, passando para o domínio da União, todas as riquezas do subsolo que ainda não fossem objeto de exploração até então.

Ou seja, conforme o art. $3^{\circ}$ do Código de Minas de 1934, a exploração dos subsolos inexplorados apenas poderia ser agora feitas mediante concessão do Governo Federal. A posterior Constituição de 1934 consagra novamente o fim do regime de acessão e a competência da União (artigos 118 e 119, CF/34).

Nesse interim, a comercialização dos combustíveis no Brasil era controlada por cinco grandes companhias estrangeiras: Royal Dutch, Standard Oil, Shell, Atlantic Refining Company, Texas Company e Caloric Company. O combustível era importado das refinarias norte-americanas e inglesas. Todavia, a solução nacionalista para a questão do petróleo ainda sofria resistências, como aponta Gilberto Bercovici (2011, p.105-6):

O próprio Ministro da Agricultura, Odilon Braga, em 1936 criticava o espírito nacionalista que teria determinado em vários países, a elaboração constitucional de dispositivos que transformaram as riquezas do subsolo em patrimônio nacional. Na sua opinião, o México, inclusive, estaria vendo sua produção petrolífera declinar em virtude da legislação de extremado nacionalismo adotada $[\ldots]$.

Posteriormente, um novo Código de Minas foi promulgado em 1940, estabelecendo o nacionalismo como fundamento e determinando que as sociedades de mineração possuíssem sócios e acionistas brasileiros ou pessoas jurídicas brasileiras. Mais à frente, em 1953, foi criada a Lei n.2.004, de 3 de outubro de 1953 (lei de criação da Petrobras), que determinou o pagamento de 4\% sobre o valor da produção terrestre de petróleo e gás natural aos estados e 1\% aos municípios em cujo território se realizasse a lavra destes hidrocarbonetos.

É com o advento da Lei n.7.453, de 27 de dezembro de 1985, que se inicia o histórico legislativo offshore (próximo à costa) do pagamento dos royal- 
ties no Brasil. Com essa, ficou determinada a obrigatoriedade do pagamento de royalties incidentes sobre a produção marítima de petróleo e gás natural, no mesmo percentual de $5 \%$ a ser repartido da seguinte maneira: $1,5 \%$ aos estados confrontantes com poços produtores; $1,5 \%$ aos municípios confrontantes com poços produtores e àqueles pertencentes às áreas geoeconômicas dos municípios confrontantes; $1 \%$ ao Ministério da Marinha; e 1\% para constituir um Fundo Especial a ser rateado entre todos estados e municípios da federação.

As duas grandes crises do petróleo alavancaram o crescimento da exploração offshore, que passou a ser considerada a melhor opção energética para os países importadores de petróleo. A primeira se deu em 1973 no Oriente Médio, quando os países produtores descobriram tratar-se de um bem não renovável e resolveram diminuir a produção do petróleo, o que gerou um aumento no preço dos barris. A segunda se deu em 1979 no Irã, com a paralização da produção de petróleo pelo país em decorrência da Revolução Islâmica, o que novamente gerou uma elevação no preço dos barris (Oil Production, 2001, p.13).

Em 1989, a Lei n.7.990 fez uma nova alteração na distribuição dos royalties. Conforme essa normativa os municípios onde existissem instalações de embarque e desembarque de petróleo ou de gás natural passariam a receber uma parcela de $0,5 \%$. Dessa maneira, o percentual dos estados passou de $4 \%$ para $3,5 \%$, quando a lavra ocorresse em terra, e o percentual do Fundo Especial foi reduzido de $1 \%$ para $0,5 \%$, quando a lavra ocorresse na plataforma continental.

Sobre essa lei, aponta Fernando Honorato dos Santos (2001, p.31-2), senão vejamos:

Incialmente previstos na Lei n.7.525 de 22.07.86, alterada pela Lei n.7.990 de 28.12.89, e hoje pagos por todos os concessionários de exploração e produção de petróleo ou gás natural e pela Sociedade por Ações Petróleo Brasileiro S.A. - PETROBRÁS, ex vi do inciso II do art. 45 da Lei n.9.478, de 06.08.97, regulamentada pelo Decreto n.2.705, de 03.08.98, os royalties são basicamente de duas origens, quais sejam: a) de produtos extraídos da Bacia Sedimentar Terrestre ou Lavra em Terra; e b) de produtos extraídos da Plataforma Continental ou Lavra na Plataforma Continental.

Os royalties de petróleo que interessam a este estudo referem-se aos da segunda origem tratada por Honorato, ou seja, os royalties de produtos extraídos da plataforma continental, que cuida das plataformas marítimas (leito e subsolo das regiões submarinas adjacentes à costa), portanto que possuem conexão ao direito do mar e seus regramentos.

Conforme o Decreto n.2.705/98, os recursos destinados aos estados e municípios são distribuídos pela Secretaria do Tesouro Nacional e creditados em suas contas específicas de titularidade, junto ao Banco do Brasil S.A., denominadas "conta especial".

O mesmo decreto dispõe que o valor a ser devido a cada mês por campo equivale à seguinte fórmula: Royalty $=10 \% \mathrm{x}$ (VTPpetróleo $\mathrm{x}$ PRPetróleo + 
VTPgásnatural x PRgásnatural), onde Royalty é o valor dos royalties decorrentes da produção do campo no mês em reais; VTPPetróleo é o volume total da produção de petróleo no campo em metros cúbicos; VTPgásnatural é o volume total da produção de gás natural do campo no mês em metros cúbicos, PRpetróleo é preço de referência do petróleo produzido do campo no mês em reais por metros cúbicos e o PRgás natural é o preço de referência do gás natural produzido no campo no mês em reais por metros cúbicos.

Após a descoberta do Pré-sal, tem-se um novo marco regulatório também na questão dos recursos provenientes de hidrocarbonetos. Em 2010, surgiu a Lei n.12.351, que dispõe sobre a exploração e a produção de petróleo, de gás natural e de outros hidrocarbonetos fluidos, sob o regime de partilha de produção, em áreas do pré-sal e em áreas estratégicas; cria o Fundo Social (FS) e dispõe sobre sua estrutura e fontes de recursos; altera dispositivos da Lei n.9.478, de 6 de agosto de 1997; e dá outras providências.

Nesse caso, debatia-se até o ano de 2013 o veto, ou não veto ao art. 64 desse regramento. Discutia-se que, da forma como redigido, o artigo não estabelece a fórmula ou a alíquota para obtenção do montante total dos recursos provenientes dos royalties. Igualmente, não é fixado o percentual desses valores que corresponderá à participação da União nem, consequentemente, o percentual que será destinado aos estados, distrito federal e municípios. Tais dados são imprescindíveis ao cálculo da parte a ser dividida entre a União e os demais entes, na forma do caput e dos incisos, e de eventual compensação, prevista no $\$ 2^{\circ}$.

A proposta também não deixa claro se as regras para divisão dos recursos se restringem aos contratos futuros ou se são aplicáveis aos já em vigor. Também se observa que não foi adotado critério para a compensação de receitas aos estados e municípios pela União. Em ambos os casos, a consequência poderia ser uma alta litigiosidade entre os diversos atores. Não trataremos aqui, neste breve espaço, dos projetos de lei que ainda não foram aprovados pela Câmara.

Vale acrescentar o veto da presidenta Dilma Rousseff ao artigo $3^{\circ}$ do Projeto de Lei do Senado n.2.565/2011, que mudaria as regras de distribuição dos royalties de petróleo para os campos já existentes e em fase de exploração e produção, no que diz respeito aos novos contratos de partilhas e produção.

Feito esse panorama sobre o cenário geral do petróleo no Brasil, passamos à questão dos royalties das Nações Unidas. Para tratar do assunto, necessário adentrarmos novamente o cenário internacional e a discussão sobre soberania e mar territorial. Pois bem: a soberania brasileira estende-se ao mar territorial, ao espaço aéreo subjacente, bem como ao seu leito e subsolo, ou seja, é exercida dentro dos limites de extensão para não extrapolar o exercício do direito de soberania.

Sobre a plataforma continental, Sergio Honorato dos Santos (2001, p.95) lembra que essa se refere às plataformas vinculadas aos continentes e passou a ser 
tratada especificamente pela Convenção das Nações Unidas sobre o Direito do Mar de 1958, em Genebra e, posteriormente, definida pela Convenção das Nações Unidas sobre o Direito do Mar de 1982 em Montego Bay, definidas a saber:

Para fins jurídicos, a plataforma continental brasileira compreende o leito e o subsolo das áreas submarinas se estendem além do seu mar territorial, em toda a extensão do prolongamento natural de seu território terrestre, até o bordo exterior da margem continental, ou até uma distância de duzentas milhas marítimas das linhas de base, a partir das quais se mede a largura do mar territorial, nos casos em que o bordo exterior da margem continental não atinja essa distância. O limite exterior da plataforma continental foi fixado em observância aos critérios estabelecidos no art. 76 da Convenção das Nações Unidas sobre o direito do mar, celebrada em Montego Bay, em 10 de dezembro de 1982.

A plataforma continental então teria o limite de 200 milhas marítimas, todavia vale dizer que a Convenção aceita a extensão das plataformas continentais para além das 200 milhas marítimas, desde que o estado costeiro apresente uma proposta de delimitação da plataforma continental jurídica para além das 200 milhas marítimas, desde que não ultrapasse 350 milhas marítimas da linha de base. Dá-se a essa o nome de plataforma continental estendida.

Nesse sentido, o Brasil deu entrada em 2004 no referido pedido junto às Nações Unidas, requerendo a extensão da plataforma continental jurídica para além das 200 milhas marítimas, para Amapá, Pará, Maranhão, Paraná, Piauí, Rio Grande do Sul, Santa Catarina, Ceará e, primordialmente, nos estados de Espírito Santo, São Paulo e Rio de Janeiro. As Nações Unidas acolheram o pedido brasileiro parcialmente, e a proposta do Brasil está em fase de nova avaliação perante a Comissão de Limites de Plataforma Continental das Nações Unidas.

Conforme dispõe o art. 82 da Convenção das Nações Unidas sobre o Direito do Mar, se o pedido for acolhido e a nova demarcação das plataformas continentais ultrapassarem as 200 milhas marítimas, o estado brasileiro poderá explorar as reservas de petróleo e gás também na plataforma estendida desde que efetue o pagamento relativo à exploração dos recursos minerais existentes royalties - sob a justificativa de que tais recursos seriam patrimônio comum da humanidade.

\section{Perspectivas do cenário após as descobertas do pré-sal}

Atualmente, os campos exploratórios do petróleo no Brasil encontram-se localizados antes das 200 milhas marítimas, todavia muitos desses campos, em especial, localizados na Bacia de Santos, já estão alocados a uma distância considerável da costa, caso, por exemplo, do Campo de Guará e Sapinhoá, que estão a aproximadamente $310 \mathrm{~km}$ da costa, ou seja, aproximadamente 167,38 milhas marítimas.

Assim como o Campo de Guará e Sapinhoá, outros como o Campo Carioca Norte (localizado a $305 \mathrm{~km}$ da Costa, ou seja, 164,68 milhas náuticas da cos- 
ta), Campo Tupi Sul (localizado a $302 \mathrm{~km}$ da costa, ou seja, aproximadamente 163 milhas marítimas), e Campos de Franco, Iara, Tupi Nordeste, Bem-te-Vi e Azulão (localizados dentre 250 a $300 \mathrm{~km}$ da costa, ou seja, a aproximadamente 161,98 milhas marítimas), já estão quase no limite geográfico permitido, ou seja, muito próximos das 200 milhas marítimas.

Da mesma maneira, o próprio polígono do pré-sal encontra-se demarcado além das 200 milhas marítimas:

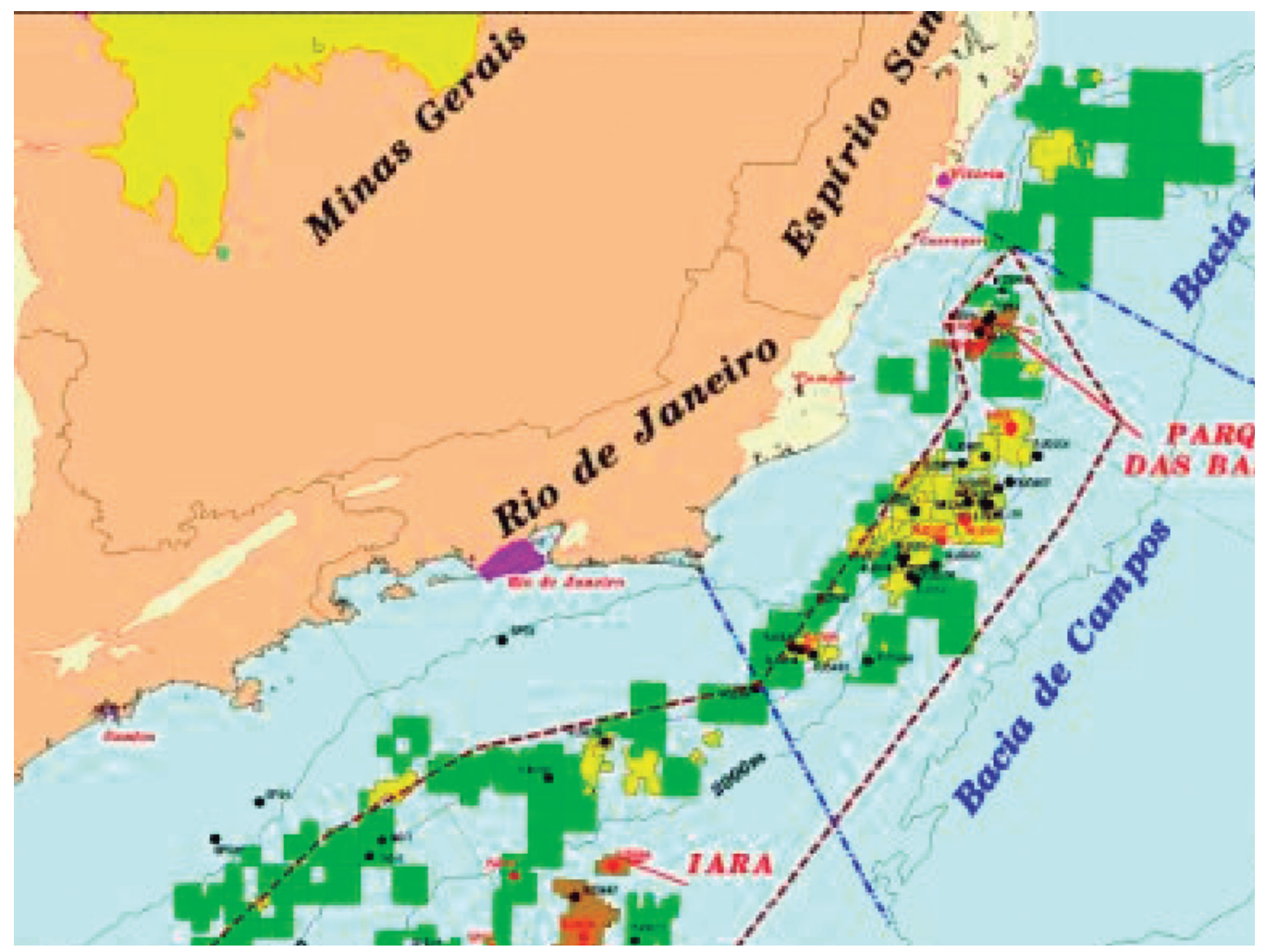

Fonte: Agência Nacional de Petróleo.

Figura 3 - Polígono do pré-sal

Ambos acontecimentos contribuem para um respaldo ainda maior da proeminente exploração de plataformas estendidas pelo estado brasileiro, bem como a aplicação das Convenções das Nações Unidas sobre o Direito do Mar de 1982 e seus dispositivos de pagamento de royalties.

\section{Considerações finais}

Por meio deste artigo, pode-se perceber a estreita relação entre o direito do mar e o viés econômico. Vale dizer, portanto, que o Direito Marítimo não apenas sofre grande influência da economia internacional, como interage diretamente com o interesse público e as demandas dos agentes econômicos e usuários dos espaços e serviços marítimos. 
Apontaram-se os diferentes diplomas legais que regulam a exploração dos recursos naturais localizados na zona marítima, destacando-se a Convenção das Nações Unidas sobre o Mar de 1982, também conhecida como a Convenção de Montego Bay, que tratou de delimitar conceitos diversos no âmbito do mar.

Dentre tais conceitos, deu-se destaque à plataforma continental, que, definida pela Convenção de Montego Bay, teria o limite de 200 milhas marítimas, podendo, todavia, ser estendida para além das 200 milhas marítimas (tornando-se, assim, "plataforma estendida"), desde que o estado costeiro apresente uma proposta de delimitação da plataforma continental jurídica para além das 200 milhas marítimas - já pleiteado pelo Brasil- desde que não ultrapasse $350 \mathrm{mi}$ lhas marítimas da linha de base. Dá-se a essa o nome de plataforma continental estendida.

Tal plataforma continental estendida está localizada na "Área" prevista na parte XI da Convenção (Parte XI), que diz respeito à exploração e a utilização dos recursos do fundo do mar e oceano e seus subsolos, fora dos limites da jurisdição nacional (da Área), onde declara que a Área e seus recursos são considerados "patrimônio comum da humanidade".

Destacou-se que tal "Área" diz respeito aos territórios além dos limites da jurisdição nacional, que foram considerados patrimônio comum da humanidade, e, portanto, não são suscetíveis de soberania ou apropriação por nenhum Estado ou pessoa física/jurídica .

No estudo de caso do estado brasileiro, verificou-se que, estando a nova demarcação das plataformas continentais além das 200 milhas marítimas, o Brasil poderá, futuramente, explorar as reservas de petróleo e gás também na plataforma estendida desde que efetue o pagamento relativo à exploração dos recursos minerais existentes - royalties - sob a justificativa de que tais recursos seriam patrimônio comum da humanidade.

Por fim, verificamos que é por intermédio da Autoridade dos Fundos Oceânicos que devem ser efetuados esses pagamentos ou contribuições, que, por sua vez, seriam distribuídos na base de critérios de repartição equitativa, tendo em conta os interesses e necessidades dos estados em desenvolvimento, particularmente entre eles, os menos desenvolvidos e sem litoral, conforme expõe a Convenção de Montego Bay, art. 82, parágrafo $4^{\circ}$.

\section{Agradecimentos}

Agradecemos ao Conselho Nacional de Desenvolvimento Científico e Tecnológico $(\mathrm{CNPq})$ pela bolsa de doutorado concedida e pelos recursos que viabilizaram este estudo; e à Faculdade de Direito da Georgetown University, Estados Unidos, principalmente na figura da professora doutora Edith Brown Weiss, pelas oportunidades de intercâmbio internacional que tornaram possível a coleta de dados e informações difíceis de ser acedidos no Brasil. Os autores também agradecem o apoio da Shell Brasil e da Fapesp, através do "Centro de Pesquisa para Inovação em Gás (conheci- 
do pelo acrônimo em inglês, Research Center for Gas Innovation - RCGI) (Fapesp Proc. 2014/50279-4), hospedado pela Universidade de São Paulo, e o importante apoio estratégico prestado pela ANP (Agência Nacional de Petróleo, Gás Natural e Biocombustíveis do Brasil) através do regulamento de promoção de atividades de P\&D.

\section{Nota}

1 De forma ilustrativa podemos citar a consolidação de diferentes fundos como "United Nations Global Disaster Fund", criado em 2008 com o intuito a ajudar nações menos desenvolvidas a mitigarem os efeitos decorrentes de desastres naturais, os quais podem vir a ser cada vez mais frequentes e severos com o avanço das mudanças climáticas. Ou, então, os vários instrumentos econômicos que têm sido criados (ou estão em fase de discussão) dentro da "United Nations Framework Convention on Climate Change (UNFCCC)".

\section{Referências}

ANDRADE, M. I. C. de. A plataforma continental brasileira. Belo Horizonte: Del Rey, 1994.

BERCOVICI, G. Direito econômico do petróleo e dos recursos minerais. São Paulo: Quartier Latin, 2011. p.105-6.

BRASIL. GOVERNO DO ESTADO. Disponível em: <http://www.brasil.gov.br / sobre/economia/ energia/petroleo-gas-natural-e-derivados/petroleo-e-derivados/ prin>. Acesso em: 21 abr. 2013.

BUCHEB, J. A. Direito do petróleo: a regulação das atividades de exploração e produção de petróleo e gás natural no Brasil. Rio de Janeiro: Lumen Juris, 2007.

CALÓGERAS, J. P. As minas do Brasil e sua legislação. Sao Paulo: Quartier, 2001. v.III, p.59-74.

CENTER FOR OCEANS LAW AND POLICY UNIVERSITY OF VIRGINIA. United Nations Convention on the law of the sea 1982: A commentary. Netherlands: Martinus Nijhoff Publishers, 1989.

CHURCHILL, R.; LOWE, A. The law of the sea. 2.ed. Manchester: Manchester University Press, 1988.

CHANDRASEKHARA, P.; RAHMATULLAH, K. The international tribunal for the law of the sea. Netherlands: Kluwer Law International, 2001.

CLAIN, L. Gulf of Maine: a disappointing first in the delimitation of a single maritime boundary. Journal of International Law, p.521-620, 1985.

COHN, G. Petróleo e nacionalismo. v.I, p.11. São Paulo: Diefel, 1968.

DIPLA, H. Les regles de droit international en matiere de dellimitation fluviale: Remise in question? RGDIP, v LXXXVIII, p.400, 1985.

EIRIKSSON, G. The international tribunal for the law of the sea. Hague: Martinus Nijhoff Publishers, 2000. 
FONSECA, J. F. da. Natureza e eficácia da sentença internacional. In: MERCADANTE, A. de A.; MAGALHÃES, J. C. Solução e prevenção de litígios internacionais. Porto Alegre: Livraria do Advogado, 1999. v.II.

FRAGA, M. O conflito entre o tratado internacional e norma de direito interno: Estudo analítico da situação do tratado na ordem jurídica brasileira. Rio de Janeiro: Forense, 1997.

GOLDEMBERG, J.; LUCON, O. Energia e meio ambiente no Brasil. 2006. Disponível em: <http://www.scielo.br/scielo.php? script=sci_arttext\&pid=S0103$-40142007000100003 \& \operatorname{lng}=p t \& n r m=i s o>$. Acesso em: 20 set. 2012

GONÇALVES, A.; RODRIGUES, G. M. A. (Org.) O direito do petróleo e gás, aspectos ambientais e internacionais. S. 1.: Editora Universitária Leupoldianum; Instituto de Estudos Avançados, 2005.

KOLOTELO, R.; WENDPAP, F. Direito internacional. Rio de Janeiro: Elsevier, 2007.

LACERDA, S. de. Curso de Direito Privado da Navegação. 3.ed. Rio de Janeiro: Freitas Bastos, 1984. p.334.

MAGALHÃES, J. C. de. O Supremo Tribunal Federal e o Direito Internacional: uma analise crítica. Porto Alegre: Livraria do Advogado, 2000.

MAROTTA RANGEL, V. Le plateau continental dans la Convention de 1982 sur le droit de la mer. Recueil de Cours, v.5, n.194, p.273-427, 1985.

. Nova Ordem Internacional: Fundos Oceânicos e Solução de Controvérsias no Direito do Mar. In: O Direito na Década de 1990: Novo Aspectos: estudos em homenagem ao Prof. Arnold Wald. São Paulo: Revista dos Tribunais, 1992.

1997.

Direito e Relações Internacionais. 5.ed. São Paulo: Revista dos Tribunais,

MASKUS, K.; REICHMAN, J. International public goods and transfer of technology under a globalized intellectual property regime. Cambridge: Cambridge University Press, 2005.

MATTOS, A. M. Direito do Mar. Rio Grande: Escola Superior de Advocacia da OAB/ RS, 17 Dez. 1998. I Congresso de Direito Ambiental Marítimo. Palestra realizada na UFRG.

MATTOS, A. M.; MEIRA, A. O novo Direito do Mar. Rio de Janeiro: Renovar, 1996.

MAZZUOLI, V. de O. As sentenças proferidas por Tribunais Internacionais devem ser homologadas pelo Supremo Tribunal Federal? Disponível em: <http://www.relnet.com. br/pgn/colunaj121.lasso>. Acesso em: 31 out. 2002.

MORAES, A. de. Regime Jurídico da concessão para exploração de petróleo e gás antural. Jus Navigandi, Teresina, ano 6, n.52, nov. 2001. Disponível em: <http://jus2.uol. com.br/doutrina/texto.asp?id=2426>. Acesso em: 25 set. 2012.

MOUTINHO DOS SANTOS, E. The Brazil and gas sector: outlook and opportunities. London: CWC Publishing Ltd. And Imedia Printed, 2001.ONU PORTUGAL. Disponível em: <http://www.onuportugal.pt/final-direito.pdf>. Acesso em: 16 out. 2002.

O’CONELL, J. The international law. Oxford: Clarendon Press, 1978.

OIL PRODUCTION. International petroleum encyclopedia. Oklahoma: Penwell, 2001. 
REZEK, F. Direito Internacional Público. 12.ed. São Paulo: Saraiva, 2010. v.1. $430+$ XXIIp .

RIBEIRO, E. Direito do Petróleo, Gás e Energia. Rio de janeiro. Elsevier, 2007.

RIBEIRO, M. R. de S. (Org.) Novos rumos do direito do petróleo. Rio de Janeiro: Renovar, 2009.

RIBEIRO, M. R. de S; BEZERRA, L. G. E. Soberania, direito internacional do mar e a exploração de petróleo e gás nas áreas offshore do Brasil. Disponível em: <http:// www.ambito-juridico.com.br /site/index.php? n_link= revista artigos_leitura\&artigo_ $\mathrm{id}=4906>$. Acesso em: 28 set. 2012.

SACHS, I. Da civilização do petróleo a uma nova civilização verde. Ministério de Minas e Energia. Plano Nacional de energia (PNE 2030). Disponível em: <www.mme.gov. br>. Acesso em: 5 abr. 2010.

SANTOS, E. M. dos. The Brazil Oil and Gas Sector: Outlook and opportunities. London: CWC Publishing Ltda., 2001.

SANTOS, S. H. dos. Royalties do petróleo à luz do direito positivo. Rio de Janeiro: Esplanada, 2001. p.31-32.

STUDIER, A. Seerechtskonferenz und drittes welt. Munchen: Weltform Verlag, 19880.

TRIBUNAL INTERNACIONAL SOBRE O DIREITO DO MAR. Disponível em: <http://www.itlos.gov> Acesso em: 10 set. 2002.

International Tribunal for the Law of the Sea. Hamburgo, Alemanha, 2002. CATÁLOGO.

ZAMITH, M. R. M.; MOUTINHO DOS SANTOS, E. Atividades Onshore no Brasil: Regulação, políticas públicas e desenvolvimento local. São Paulo: Annablume, 2007.

RESUMO - O presente trabalho tem por objeto abordar os aspectos de regulação internacional do petróleo, mais precisamente aqueles previstos na Convenção das Nações Unidas sobre o direito do mar de 1982, que definem a obrigatoriedade do pagamento de royalties às Nações Unidas advindos da exploração dos hidrocarbonetos nas plataformas estendidas. Utiliza o método dedutivo e o tipo de pesquisa exploratório e comparativo, o artigo dividiu-se em três capítulos. Após introduzir o leitor ao tema, abordando-se as particularidades do direito do mar e seu viés de exploração econômica, os autores discorrem sobre a questão com uma dimensão da regulação quase sempre ausente da formulação de políticas energéticas. Essa discussão é apresentada a partir do estudo de caso do Brasil. Para tanto, cuida de apresentar a importância do setor petrolífero e o histórico da exploração offshore no Brasil. Adentra-se em seguida a temática da distribuição dos royalties entre o estado nacional e as nações unidas. No desenvolvimento da questão são trazidos à tona o possíveis cenários entre o futuro da exploração petrolífera no Brasil e os resultados da aplicação da regulação internacional pela Convenção das Nações Unidas sobre o Direito do Mar de 1982. Por fim, chegou-se à conclusão de que algumas plataformas de petróleo já estão localizadas próximas do limite das 200 milhas marítimas e o polígono do pré-sal também encontra-se adentrando as 200 milhas marítimas, o que demonstra uma necessidade de uma abordagem imparcial sobre os prós e contras do posicionamento brasileiro, analisando os possíveis cenários futuros. 
PALAVRAS-CHAVE: Royalties, Petróleo, Direito do Mar, Regulação Internacional, Nações Unidas.

ABSTRACT - This papers seeks to verify aspects of the international regulation of oil, specifically those contained in the 1982 United Nations Convention on the Law of the Sea that refer to the obligation to pay royalties to the United Nations on the exploration by the Brazilian government of hydrocarbons in extended platforms. The deductive method and exploratory and comparative research were used. After identifying how the work was carried out, it discusses the issue of law of the sea and the economic exploitation discourses on the theme, their motivation and the context of work to be investigated. The authors also discuss the issue within the dimension of regulation being almost always absent from the formulation of energy policies. The discussion is grounded on a case study of Brazil and presents the importance of the oil industry, the history of offshore exploration in Brazil, and even the distribution of royalties between the national state and the United Nations. In the development of this issue, possible scenarios are brought to light regarding the future of offshore oil exploration in Brazil and the results of enforcement of international regulation by the 1982 United Nations Convention on the Law of the Sea. Finally, we reach the conclusion that some oil rigs are already located near the 200 nautical miles limit and that the polygon of the pre-salt oils reserves is also entering this limit, demonstrating the need for an impartial reckoning of the pros and cons of Brazil's position by analyzing possible future scenarios.

KEYWORDS: Royalties, Oil, Sea law, International regulation, United Nations.

Thaiz da Silva Vescovi Chedid é doutora em Energia pela Universidade de São Paulo em colaboração com Georgetown University Law School, mestre em Direitos e Garantias Fundamentais pela Faculdade de Direito de Vitória. Professora da Universidade Vila Velha (UVV-ES). @ - thaiz.vescovi@uvv.br / thaizvescovi@hotmail.com / https://orcid.org/0000-0003-3725-7072

Edmilson Moutinho dos Santos é professor associado no Instituto de Energia e Ambiente da Universidade de São Paulo; presidente da Comissão de Pós-Graduação do IEE/USP; Coordenador do Programa de Economia e Políticas Energéticas no Research Center for Gas Innovation, RCGI, da Universidade de São Paulo.

@ - edsantos@iee.usp.br / https://orcid.org/0000-0003-3088-855X

Recebido em 11.2.2014 e aceito em 12.6.2018.

${ }^{\mathrm{I}}$ Universidade Vila Velha, Vila Velha, Espírito Santo, Brasil.

II Instituto de Energia e Ambiente, Universidade de São Paulo, São Paulo, São Paulo, Brasil. 